\title{
Intractable diarrhoea associated with secondary amyloidosis in rheumatoid arthritis
}

\author{
Yasuaki Okuda, Kiyoshi Takasugi, Tetsu Oyama, Hiroko Oyama, Shigeru Nanba, \\ Takeshi Miyamoto
}

\begin{abstract}
Objective-To examine the clinical characteristics of intractable diarrhoea associated with secondary amyloidosis in rheumatoid arthritis (RA).

Methods-Of 179 RA patients with biopsy confirmed secondary amyloidosis, 24 cases (23 women and one man) with intractable diarrhoea lasting for more than one month were retrospectively evaluated.

Results-The mean (SD) duration of diarrhoea was 87 (64) days. Prodromal symptoms of gastrointestinal dysfunction $(n=21)$ and impaired peristalsis $(n=16)$ were observed. Laboratory data showed hypoproteinaemia $(4.7(0.85)$ g/dl) caused by malabsorption or protein loss and high values of $C$ reactive protein (17.0 (9.3) mg/dl). Recurrence of intractable diarrhoea $(n=4)$ and transition from intractable diarrhoea to other gastrointestinal problems of amyloidosis (ischaemic colitis $(n=2)$ and intestinal pseudoobstruction $(n=4)$ ) were observed. In 19 patients ( 25 episodes) the duration of intravenous hyperalimentation at remission (18 episodes) was 68 (52) days. Corticosteroid pulse therapy was administered to 10 patients (11 times) and the time elapsed from the end of corticosteroid pulse therapy to the end of diarrhoea was 18 (14) days. One and five year survival rates after the onset of intractable diarrhoea were $73.4 \%$ and $38.9 \%$. Seven of 13 patients (54\%) had died as a result of infectious diseases.
\end{abstract}

Conclusion-Intractable diarrhoea associated with secondary amyloidosis in RA is a serious clinical entity and the prognosis is poor. Although it is assumed that intravenous hyperalimentation treatment and corticosteroid pulse therapy are favourable regimens for intractable diarrhoea, the patients should be monitored for possible infectious complications.

(Ann Rheum Dis 1997;56:535-541)

Secondary amyloidosis is a disease characterised by extracellular deposition of amyloid A protein, which is the result of excessive generation and abnormal degradation of serum amyloid A (SAA). ${ }^{1}$

Recent clinical studies have shown that the prevalence of amyloidosis proved by biopsy in rheumatoid arthritis (RA) patients is about $10 \% .^{2-5}$ Among the complications of RA, secondary amyloidosis is one of the most severe complications in the late stages of RA because of its poor prognosis. ${ }^{6-8}$

Secondary amyloidosis commonly affects the gastrointestinal tract as well as the kidneys, as shown by various clinical symptoms that include anorexia, nausea, vomiting, feeling of abdominal fullness, abdominal pain, diarrhoea, melaena, and perforation of the gastrointestinal tract. ${ }^{4-13}$ In particular prolonged intractable diarrhoea is severe, distressing, and often unresponsive to treatment. Thus, it is essential to clarify the clinical characteristics, the treatment, and the prognosis of intractable diarrhoea associated with secondary amyloidosis in patients with RA. While case reports have been reported, ${ }^{14-17}$ we believe this is the first attempt to describe a retrospective series in a defined population with secondary amyloidosis caused by RA. In this case record review, clinical features and prognosis are examined.

\section{Methods}

PATIENT SELECTION

The inclusion criteria for this retrospective study were as follows: RA diagnosed according to the criteria for the classification of RA of the American College of Rheumatology (formerly the American Rheumatism Association) of $1987,{ }^{18}$ and the presence of intractable diarrhoea. Intractable diarrhoea was defined as sustained watery diarrhoea that did not respond to treatment with the antidiarrhoeal drugs such as albumin tannate, berberine, loperamidehydrochloride for more than one month and having no other cause of diarrhoea than secondary amyloidosis, such as bacterial enterocolitis or pancreatic diseases. The termination of diarrhoea was defined when a formed stool was observed.

For the patients who survived, the mean (SD) time from the diagnosis of amyloidosis to the final assessment was 1606 (1172) days (median 1681, 102-3260), and the mean (SD) time from the onset of intractable diarrhoea to the final assessment was 1494 (1221) days (median 1684, 56-3312)

\section{STUDY DESIGN}

Tissue staining with Congo red and antiserum against amyloid A protein were routinely performed to establish the diagnosis of secondary amyloidosis.

All the patients with intractable diarrhoea had deposits of amyloid A protein on the gastrointestinal tract mucosa (stomach, duodenum or colon). When specimens confirmed positive staining for amyloid deposits on gastrointestinal tracts, they were divided
Accepted for publication 11 June 1997 
Table 1 Clinical features in 24 patients with rheumatoid arthritis and intractable diarrhoea caused by secondary amyloidosis

$\begin{array}{lc}\text { Age at diagnosis of amyloidosis, mean (SD) y (median; range) } & 57(9)(57 ; 40-74) \\ \text { Duration of arthritis at diagnosis of amyloidosis, mean (SD) y } & 13(5)(13 ; 3-22) \\ \quad \text { (median; range) } & 100 \\ \text { Articular erosions (\%) } & 92 \\ \text { Rheumatoid factor (\%) } & 69(21)(79 ; 38-119 \\ \text { Lansbury activity index mean (SD) (median; range) } \dagger & 8.9(5.6)(11.6 ; \\ \text { CRP, mg/dl mean (SD) (median; range) } \ddagger & 0.6-22.5) \\ & 0.6(0.2)(0.8 ; 0.3-1.2) \\ \text { CRN, mg/dl mean (SD) (median; range) } \ddagger & 17 \\ \text { Proteinuria (\%) } & 8\end{array}$

$\mathrm{CRP}=\mathrm{C}$ reactive protein; $\mathrm{CRN}=$ creatinine. ${ }^{\star}$ Rheumatoid factor in serum was measured by the rheumatoid arthritis haemagglutination test. †Patients were evaluated for four parameters (morning stiffness, grip strength, joint count, and erythrocyte sedimentation rate) at the nearest point before onset of intractable diarrhoea. $\ddagger$ Values at nearest point before onset of intractable diarrhoea. based on the presence of typical clinical symptoms (abdominal distension, complete failure to evacuate stool, and flatus) and abdominal $x$ ray findings (gaseous distension of small intestine and colon) consistent with intestinal pseudo-obstruction.

STATISTICAL ANALYSIS

The survival time was calculated from the date of the onset of intractable diarrhoea. For the cases of repeated, multiple episodes of intractable diarrhoea, the survival time was calculated from the date of onset of the first episode.

In comparison with the non-intractable diarrhoea group the survival time was calculated from the date on which the amyloidosis was diagnosed. The non-intractable diarrhoea group consists of all the patients with secondary amyloidosis and RA who had never experienced intractable diarrhoea. Survival was assessed by life table analysis. Survival curves were calculated by the Kaplan-Meir method.The prognostic value of factors (measured at the onset of intractable diarrhoea) for survival was investigated using log rank tests.Correlations were sought using a ranked Spearman correlation coeficient. Statistical evaluation of the data was performed using StatView J4.05 software for Macintosh. Probabilities $<0.05$ were considered significant.

toms such as abdominal pain, nausea, anorexia or transient diarrhoea and the presence of other possible causes of intractable diarrhoea were investigated from the clinical records.

We investigated the cases in which intestinal pseudo-obstruction or ischaemic colitis occurred during the course or after the improvement of intractable diarrhoea. The diagnosis of ischaemic colitis was made when abdominal pain and melaena occurred and colonoscopic examination showed mucosal changes (oedema, redness) and longitudinal ulcers consistent with ischaemic colitis. The diagnosis of intestinal pseudo-obstruction was

\section{Results}

CLINICAL FEATURES

During the years from 1985 to 1995, a total of 3415 patients with RA were seen at the Centre for Rheumatic Diseases of Dohgo Spa Hospital.

Among the 179 cases of biopsy confirmed secondary amyloidosis treated at our centre between 1985 and 1995, there were 24 patients (23 women and one man) who fulfilled the inclusion criteria. In 15 cases, diagnosis of sec-

Table 2 Clinical findings and laboratory data of the 24 rheumatoid arthritis patients with intractable diarrhoea caused by secondary amyloidosis

\begin{tabular}{|c|c|c|c|c|c|c|}
\hline Patient & $A g e^{\star} / \operatorname{sex}$ & $\begin{array}{l}\text { Duration of diarrhoea } \\
\text { (days) }\end{array}$ & $\begin{array}{l}\text { Frequency of } \\
\text { diarrhoea (times) }\end{array}$ & Nadir TP† (g/dl) & Nadir Albt (g/dl) & $\begin{array}{l}\operatorname{Max} C R P \mp \\
(m g / d l)\end{array}$ \\
\hline 1 & $56 / \mathrm{F}$ & 54 & 6 & 3.8 & 1.8 & 13.3 \\
\hline 2 & $41 / \mathrm{F}$ & 32 & 5 & 6.2 & 3.1 & 6.3 \\
\hline 3 & $53 / \mathrm{F}$ & 81 & 8 & 5.4 & 2.2 & 18.7 \\
\hline 4 & $60 / \mathrm{F}$ & 69 & 5 & 5.6 & 2.4 & 12.0 \\
\hline 5 & $74 / \mathrm{F}$ & 135 & 16 & 3.4 & 1.3 & 22.5 \\
\hline 6 & $57 / \mathrm{F}$ & 83 & 7 & 5.4 & 2.5 & 8.3 \\
\hline 7 & $67 / \mathrm{F}$ & 36 & 6 & 4.5 & 2.3 & 8.5 \\
\hline 8 & $46 / \mathrm{F}$ & 50 & 8 & 5.5 & 2.6 & 10.7 \\
\hline 9 & $68 / \mathrm{F}$ & 94 & 9 & 4.8 & 1.7 & 6.5 \\
\hline 10 & $40 / \mathrm{F}$ & 116 & 6 & 5.1 & 2.4 & 24.4 \\
\hline 11 & $53 / \mathrm{F}$ & 177 & 10 & 3.0 & 1.5 & 24.3 \\
\hline 12 & $56 / \mathrm{F}$ & 258 & 8 & 4.8 & 2.6 & 18.4 \\
\hline 13 & $50 / \mathrm{F}$ & 268 & 11 & 4.8 & 1.9 & 39.5 \\
\hline 14 & $71 / \mathrm{F}$ & 80 & 8 & 4.7 & 2.6 & 8.2 \\
\hline 15 & $44 / \mathrm{F}$ & 70 & 4 & 4.5 & 2.3 & 21.5 \\
\hline 16 & $71 / M$ & 74 & 6 & 3.3 & 1.9 & 25.2 \\
\hline 17 & $54 / \mathrm{F}$ & 41 & 8 & 4.0 & 2.4 & 22.0 \\
\hline 18 & $60 / \mathrm{F}$ & 42 & 5 & 5.5 & 2.3 & 33.9 \\
\hline 19 & $58 / \mathrm{F}$ & 46 & 8 & 5.4 & 2.7 & 15.9 \\
\hline 20 & $54 / \mathrm{F}$ & 54 & 9 & 4.4 & 1.6 & 9.4 \\
\hline 21 & $61 / \mathrm{F}$ & 62 & 5 & 5.2 & 2.4 & 7.1 \\
\hline 22 & $59 / \mathrm{F}$ & 92 & 7 & 3.7 & 2.0 & 8.5 \\
\hline 23 & $61 / \mathrm{F}$ & 41 & 5 & 5.0 & 2.2 & 13.2 \\
\hline 24 & $51 / \mathrm{F}$ & 36 & 6 & 4.0 & 1.9 & 29.6 \\
\hline
\end{tabular}

$\mathrm{TP}=$ total protein; $\mathrm{Alb}=$ albumin; $\mathrm{CRP}=\mathrm{C}$ reactive protein. ${ }^{\star}$ Age at diagnosis of amyloidosis. $\uparrow$ Nadir values during the course of intractable diarrhoea. $¥$ Maximum values during the course of intractable diarrhoea. 
ondary amyloidosis was established at the time when they developed intractable diarrhoea. Gastrointestinal symptoms such as abdominal pain, anorexia but not persistent diarrhoea led to the diagnosis in five cases. The remaining four cases were discovered on routine endoscopic gastrointestinal screening.

Table 1 summarises the main RA features of the 24 cases. Only one case showed the creatinine concentration in excess of $1.0 \mathrm{mg} / \mathrm{dl}$ at the onset of intractable diarrhoea. Minor proteinuria $(<1 \mathrm{~g} / 24 \mathrm{~h})$ was seen in four cases. None of the cases showed heart failure, low voltage electrocardiogram or hypothyroidism. Many cases showed increased Lansbury activity indices and $\mathrm{C}$ reactive protein values. Prodromal symptoms of gastrointestinal dysfunction were observed in 21 cases (88\%), and the symptoms were repeatedly observed from one year or several months before the onset of intractable diarrhoea.

Other possible causes of the induction of intractable diarrhoea were recognised in six cases including three cases of infection, two cases of operation, and one case of extraarticular manifestation (myocarditis). The three episodes of infection were purulent arthritis of left knee, meningitis caused by Candida albicans, and hepatitis caused by cytomegalovirus. The two cases of intractable diarrhoea caused by operation started to manifest intractable diarrhoea 14 days after the synovectomy of bilateral knees and 24 days after the fusion of cervical spine, respectively. Greatly increased $\mathrm{C}$ reactive protein values were observed in all six cases before the onset of intractable diarrhoea (median; $14.4 \mathrm{mg} / \mathrm{dl}$, range; $6.3-22.5 \mathrm{mg} / \mathrm{dl}$ ).

The abdominal features during the course of intractable diarrhoea included pain in 22 cases $(92 \%)$, nausea in $21(88 \%)$, vomitting in 20 $(83 \%)$, and distension in $16(67 \%)$.

Table 2 summarises the clinical findings and the laboratory data of the 24 cases. The duration of diarrhoea was 87 (64) days (median 150, range 32-268) and the frequency of diarrhoea was 7 (3) times/day (median 10 times/day, range 4-16 times/day). The nadir total protein concentration and the nadir albumin concentration during the course of diarrhoea were $4.7(0.85) \mathrm{g} / \mathrm{dl}$ (median 4.6 $\mathrm{g} / \mathrm{dl}$, range $3.0-6.2 \mathrm{~g} / \mathrm{dl})$ and $2.2(0.43) \mathrm{g} / \mathrm{dl}$ (median $2.2 \mathrm{~g} / \mathrm{dl}$, range $1.3-3.1 \mathrm{~g} / \mathrm{dl}$ ), respectively. The maximum $\mathrm{C}$ reactive protein value during the course of intractable diarrhoea was very high $(17.0(9.3) \mathrm{mg} / \mathrm{dl}$; median $22.9 \mathrm{mg} / \mathrm{dl}, 6.3-39.5 \mathrm{mg} / \mathrm{dl})$.

Table 3 summarises the endoscopic findings of 16 cases in which upper gastrointestinal or colon endoscopy was performed during the course of intractable diarrhoea. Abnormal findings were observed in the stomach or duodenum or colon in all the cases. Coarse mucosal appearance such as fine granular elevation or irregular mucosa was seen in 12 cases $(75 \%)$ and mucosal injuries (ulcer, erosion, bleeding or redness ) were observed in 11 cases $(69 \%)$ in upper gastrointestinal or colon endoscopy (figs 1 and 2). On the other hand, in the non-intractable diarrhoea patients
Table 3 Endoscopic findings in rheumatoid arthritis patients during intractable diarrhoea caused by secondary amyloidosis

\begin{tabular}{llll}
\hline \multirow{4}{*}{$\begin{array}{l}\text { Patient } \\
n o\end{array}$} & \multicolumn{2}{l}{ Endoscopic findings } \\
\cline { 2 - 3 } & Stomach & Duodenum & Colon \\
\hline 2 & NA & ER,RED & \\
3 & ER,RED & ER,RED & ER,RED (des,sig,rec) \\
4 & CMA,BL & CMA & \\
5 & CMA & CMA & CMA (rec) \\
7 & NA & ER,CMA & NA \\
9 & UL,ER & UL,CMA & NA \\
10 & NA & CMA & NA \\
11 & BL,UL & CMA & CMA (des) \\
12 & CMA & CMA & \\
13 & CMA,ER & CMA & ER,RED (rec) \\
18 & CMA & NA & \\
19 & RED & CMA & NA \\
20 & UL,RED & NA & \\
21 & RED,BL,CMA & NA & \\
22 & CMA & CMA & ER,RED (rec) \\
23 & RED & NA & ER,R
\end{tabular}

CMA = coarse mucosal appearance $; \mathrm{ER}=$ erosion; $\mathrm{UL}=$ ulcer; $\mathrm{RED}=$ redness; $\mathrm{BL}=$ bleeding; $\mathrm{NA}=$ no abnomality; rec = rectum; sig = sigmoid colon; des = descending colon.

on whom upper gastrointestinal or colon endoscopy were perfomed at the time of diagnosis of secondary amyloidosis, coarse mucosal appearance was seen in 21 of 121 cases $(17 \%)$, and mucosal injuries were observed in 67 of 121 cases (55\%).

Gastroduodenal biopsies were conducted on all 16 cases and considerable deposits of amyloid were found in gastrointestinal tissues. In the eight cases in which no endoscopy was performed during the course of intractable diarrhoea, considerable deposits of amyloid from gastrointestinal tracts had been found before the onset of intractable diarrhoea. On the other hand, in the non-intractable diarrhoea patients who were diagnosed as secondary amyloidosis by gastrointestinal biopsy considerable deposits of amyloid were observed in 63 of 121 patients (52\%).

Recurrence of intractable diarrhoea after remission or other types of gastrointestinal manifestations of amyloidosis was observed in nine cases. Figure 3 shows the transition patterns. In four cases of recurrent intractable diarrhoea, six episodes occurred and the time

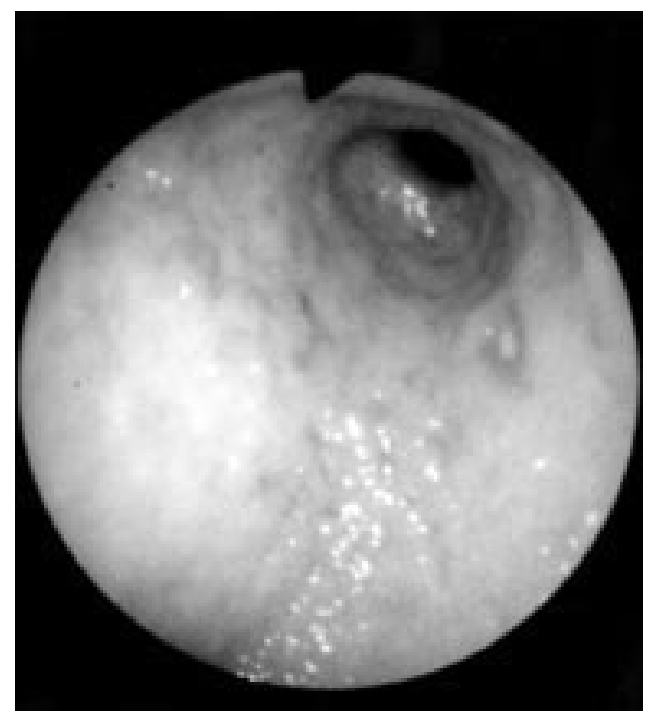

Figure 1 Multiple erosions, redness, and coarse irregular elevated mucosa are seen in the antrum of the stomach. 


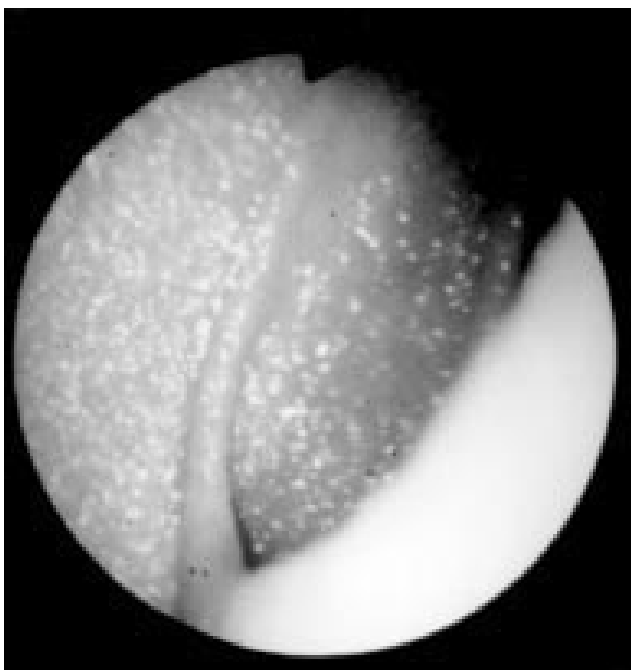

Figure 2 Endoscopy shows fine granular elevations in the second portion of the duodenum.

elapsed before the next episode was 6 (2.8) months (3-10). Ischaemic colitis after the remission of intractable diarrhoea was observed in two cases and the time elapsed from the remission of intractable diarrhoea until the onset of ischaemic colitis was 26 and 24 months, respectively. Intestinal pseudoobstruction during the course of intractable diarrhoea was observed in four cases, among which one case showed intestinal pseudoobstruction during the third episode of intractable diarrhoea.

Treatment regimens of intractable diarrhoea were determined by the physician responsible for care. However, for the cases with frequent watery diarrhoea and having severe nausea and severe hypoalbuminaemia, the following treatment regimens were conducted (table 4). To allow the impaired intestine to rest and to reduce intestinal inflammation, these patients received intravenous hyperalimentation in combination with a moderate dose of corticosteroids (10 to $30 \mathrm{mg} /$ day of prednisolone) . For cases showing no remission of watery diarrhoea with this regimen, corticosteroid pulse therapy $(100 \mathrm{mg} \times 3$ days of betamethasone or $125 \mathrm{mg} \times 3$ days of methylpred-

\begin{tabular}{|c|c|c|}
\hline \multicolumn{2}{|c|}{$\begin{array}{l}\text { Patterns } \\
\text { (Patient number, interval of episodes of gastrointestinal amyloidosis (months)) }\end{array}$} & Cases \\
\hline Diarrhoea & $\longrightarrow \quad \begin{array}{l}\text { pseudo-obstruction } \\
\text { (no interval) }\end{array}$ & 3 \\
\hline Diarrhoea & $\begin{array}{l}\longrightarrow \text { diarrhoea (patient 3,4 months; patient } 11 \text {, } \\
7 \text { months) }\end{array}$ & 2 \\
\hline Diarrhoea & $\begin{array}{l}\longrightarrow \quad \text { ischaemic colitis } \\
\text { (patient } 5,26 \text { months; patient } 12,24 \text { months) }\end{array}$ & 2 \\
\hline Diarrhoea & $\rightarrow \begin{array}{l}\text { diarrhoea } \longrightarrow \text { diarrhoea } \\
\text { (patient } 10,3 \text { months and } 10 \text { months) }\end{array}$ & 1 \\
\hline Diarrhoea & $\rightarrow \begin{array}{l}\text { diarrhoea } \\
\text { (patient } 7,4 \text { months and } 8 \text { months) }\end{array}$ diarrhoea $\rightarrow$ pseudo-obstruction & 1 \\
\hline
\end{tabular}

Figure 3 Patterns of relapse of intractable diarrhoea and transition from intractable diarrhoea to other types of gastrointestinal manifestations of amyloidosis (ischaemic colitis or intestinal pseudo-obstruction).

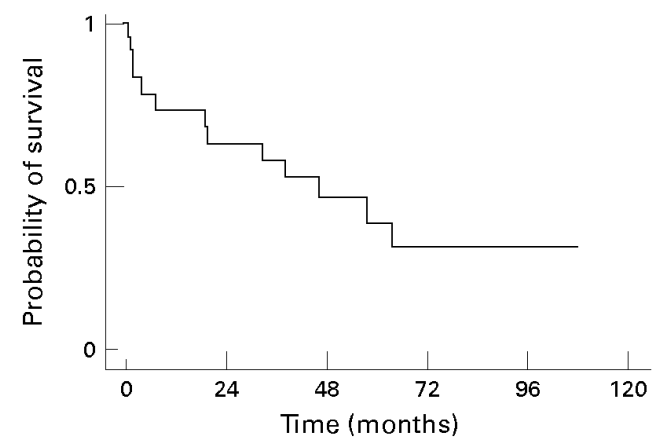

Figure 4 Survival rate of the 24 rheumatoid arthritis patients with intractable diarrhoea associated with secondary amyloidosis.

nisolone) was administered after confirmation of absence of infectious diseases.

Intravenous hyperalimentation treatment was performed in 19 cases, 25 times, and the duration of intravenous hyperalimentation treatment of 18 episodes at the remission, excluding the deceased cases, was 6852 days (median 126, range 29-223).

The corticosteroid pulse therapy was conducted in 10 cases, 11 times. The duration of diarrhoea from its onset to the corticosteroid pulse therapy in nine cases with 10 episodes, excluding one deceased case, was 77 (76) days (median 135, range 17-253) and the duration from the end of corticosteroid pulse therapy to the end of diarrhoea was 18 (14) days (median 26.5, range 3-50).

Thirteen patients (54\%) died during the study period. Table 5 summarises the causes of death. The cause of death was confirmed mainly by the clinical record. The duration from the diagnosis of amyloidosis until death and that from the onset of intractable diarrhoea until death were 843 (618) days (median 1138, range 142-2133) and 706 (728) days (median 1089, range 40-2138) respectively. Seven patients died during the course of intractable diarrhoea. One died of congestive heart failure during the third course of intractable diarrhoea. Another died because of septicaemia and one died of pneumonia after transition to intestinal pseudoobstruction. One patient with septicaemia died after the transition to intestinal pseudoobstruction during the course of the third episode of intractable diarrhoea.

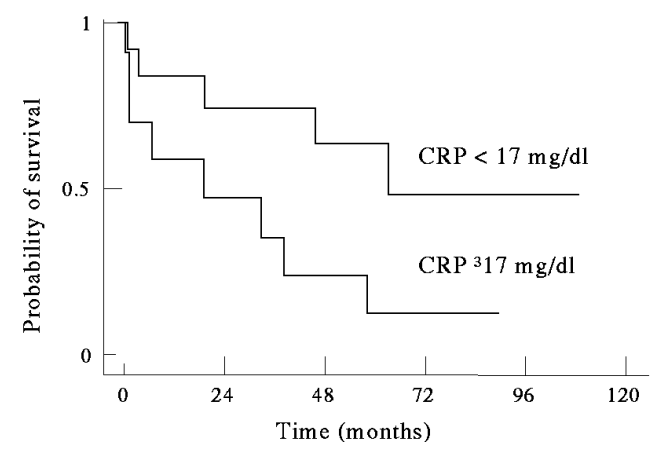

Figure 5 Survival of the 24 rheumatoid arthritis patients with intractable diarrhoea associated with secondary amyloidosis, according to $C$ reactive protein $(C R P) \geq 17$ $\mathrm{mg} / \mathrm{dl}$ or $\mathrm{CRP}<17 \mathrm{mg} / \mathrm{dl}$. 
Table 4 Treatment of intractable diarrhoea caused by secondary amyloidosis in 24 rheumatoid arthritis patients

\begin{tabular}{|c|c|c|c|c|c|c|c|}
\hline Patient & $I V H$ & $\begin{array}{l}\text { IVH } \\
\text { duration } \\
\text { (days) }\end{array}$ & $\begin{array}{l}\text { CS maximum } \\
\text { dose } \\
(m d / d a y)^{*}\end{array}$ & $\begin{array}{l}\text { CS } \\
\text { pulse }\end{array}$ & $\begin{array}{l}\text { Duration of } \\
\text { diarrhoea } \\
\text { (days)t }\end{array}$ & $\begin{array}{l}\text { Duration of } \\
\text { pulse (days) } \neq\end{array}$ & Outcome \\
\hline 1 & + & 35 & 20 & - & & & $\mathrm{D} \|$ \\
\hline 2 & - & & 10 & - & & & $S$ \\
\hline 3 & + & 44 & 10 & - & & & $S$ \\
\hline 4 & + & 73 & 10 & M125 & 42 & 17 & $\mathrm{~S}$ \\
\hline 5 & + & 87 & 20 & - & & & S \\
\hline 6 & - & & 30 & - & & & $S$ \\
\hline \multirow[t]{3}{*}{7} & - & & 5 & - & & & $S$ \\
\hline & + & 40 & 25 & - & & & $S$ \\
\hline & + & 21 & 20 & M125 & 92 & 14 & $\mathrm{D} \|$ \\
\hline 8 & - & & 0 & - & & & $S$ \\
\hline 9 & + & 33 & 15 & - & & & $\mathrm{S}$ \\
\hline \multirow[t]{2}{*}{10} & + & 76 & 20 & - & & & S \\
\hline & + & 39 & 20 & - & & & D \\
\hline \multirow[t]{2}{*}{11} & + & 182 & 20 & $\mathrm{~B} 100$ & 166 & 11 & $S$ \\
\hline & + & 64 & 20 & B100 & 66 & 23 & $S$ \\
\hline 12 & + & 223 & 10 & B100 & 253 & 3 & $S$ \\
\hline 13 & + & 151 & 5 & - & & & D \\
\hline 14 & + & 51 & 20 & B100 & 30 & 50 & $S$ \\
\hline 15 & + & 27 & 20 & - & & & $\mathrm{D} \|$ \\
\hline 16 & + & 37 & 10 & - & & & D \\
\hline 17 & + & 4 & 17 & M125 & 34 & - & D \\
\hline 18 & + & 40 & 10 & - & & & $\mathrm{S}$ \\
\hline 19 & + & 30 & 10 & M125 & 17 & 29 & S \\
\hline 20 & - & & 0 & - & & & $S$ \\
\hline 21 & - & & 10 & M125 & 59 & 3 & S \\
\hline 22 & + & 56 & 5 & - & & & $S$ \\
\hline 23 & + & 29 & 20 & M125 & 30 & 11 & S \\
\hline 24 & + & 50 & 20 & $\mathrm{~B} 100$ & 19 & 17 & $S$ \\
\hline
\end{tabular}

IVH=intravenous hyperalimentation, CS=corticosteroid, $M 125=$ methylprednisolone $125 \mathrm{mg} \times$ 3 days, $\mathrm{B} 100=$ betamethazone $100 \mathrm{mg} \times 3$ days, $\mathrm{S}=$ survival, $\mathrm{D}=$ death. ${ }^{\star}$ Maximum daily dose of prednisolone. †Duration of diarrhoea before start of corticosteroid pulse treatment. $\ddagger$ Duratio of diarrhoea after the end of corticosteroid pulse treatment. \$Outcome of patient during the course of intractable diarrhoea. $\|$ Denotes transition from intractable diarrhoea to intestinal pseudo-obstruction before death.

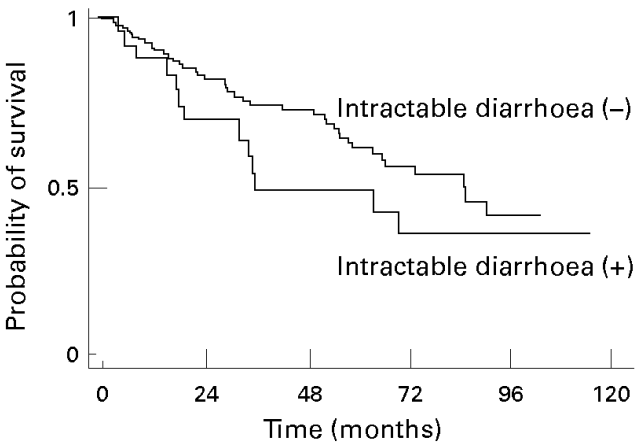

Figure 6 Survival of 179 patients with rheumatoid arthritis associated with secondary amyloidosis, according to the presence or absence of intractable diarrhoea.

significant association between decreased survival and RA features before the onset of intractable diarrhoea (Lansbury activity index, the concentration of $\mathrm{C}$ reactive protein, gastrointestinal symptoms ), duration of diarrhoea, frequency of diarrhoea, hypoalbuminaemia, the concentration of creatinine, relapse of intractable diarrhoea or transition to other types of gastrointestinal manifestation of amyloidosis and corticosteroid pulse therapy. Although not statistically significant by $\log$ rank test $(p=0.0704)$, survival curves from the diagnosis of secondary amyloidosis showed lower values in the intractable diarrhoea group than in the non-intractable diarrhoea group (five year survival, $47 \%$ versus $61.1 \%$ ) (fig 6 ).

Figure 4 shows the overall survival curve. The percentages of patients who survived at least one, three, and five years after the onset of intractable diarrhoea were $73.4 \%, 57.7 \%$, $38.9 \%$, respectively.

Analysis of the prognostic value of factors for survival indicated that both a high $\mathrm{C}$ reactive protein value $(\mathrm{CRP} \geq 17 \mathrm{mg} / \mathrm{dl}$ (mean value)) during the course of intractable diarrhoea $(\mathrm{p}=0.0395)$ (fig 5) and intravenous hyperalimentation treatment $(p=0.0484)$ were significantly correlated with decreased survival. Their five year survival rates were $11.8 \%$ (n $=11)$, versus $63.9 \%(n=13)$ when $C$ reactive protein was $<17 \mathrm{mg} / \mathrm{dl}$ and $27.4 \%(\mathrm{n}=19)$, versus $75.0 \%(\mathrm{n}=5)$ with no intravenous hyperalimentation treatment, respectively. Hypoproteinaemia (total protein $<4.7 \mathrm{~g} / \mathrm{dl}$ ) and short duration of arthritis at diagnosis of amyloidosis ( $<13$ years) were associated with a trend toward decreased survival $(\mathrm{p}=0.101$ and 0.1566 , respectively). But no correlation was seen between survival time and concentration of total protein $(\rho=346, p=0.0974)$ or duration of arthritis at diagnosis of amyloidosis $(\rho=0.204, p=0.3274)$. We found no

Table 5 Cause of death of 13 rheumatoid arthritis patients with intractable diarrhoea caused by secondary amyloidosis

Death during the course of intractable diarrhoea Septicaemia Pneumonia

Congestive heart failure

Death during the follow up

Chronic renal failure

Pneumonia

Pneumonitis

Unknown (sudden death at home)

\section{Discussion}

There is no detailed description of the clinical characteristics of patients with RA before the onset of intractable diarrhoea associated with secondary amyloidosis in previous case reports. ${ }^{14-17}$ Our present retrospective study showed that before the onset of diarrhoea, most patients showed high activity of arthritis and repeated prodromal gastrointestinal symptoms. Furthermore, some cases showed possible causes of induction of intractable diarrhoea (that is, operation, infection or extraarticular manifestation). SAA, which is the precursor of amyloid A protein, is known to be synthesised in the liver and the process is stimulated by macrophage derived cytokines such as interleukin 1 , interleukin 6 or tumour necrosis factor, thus it rapidly increases in blood at the time of acute inflammation in parallel with acute phase proteins such as $\mathrm{C}$ reactive protein..$^{20}$ It is considered that high activity of arthritis, infection, surgery and extraarticular manifestation of RA induce a rapid increase of SAA and promote the deposit of amyloid, which might contribute to the onset of intractable diarrhoea.

With regard to renal function, most patients had normal values of creatine. Even in one patient who had increased concentrations of creatine at the time of the onset of intractable diarrhoea, those values returned to normal after recovery from dehydration. It is generally assumed that intractable diarrhoea tends to manifest earlier than renal dysfunction. In fact, in 15 cases $(63 \%)$ the opportunity to diagnose amyloidosis was the onset of intractable 
diarrhoea. Other opportunities to diagnose amyloidosis were at the time of the endoscopic upper gastrointestinal screening of amyloidosis and the onset of other digestive symptoms. There was no case of nephropathy such as renal failure or massive proteinuria before the onset of intractable diarrhoea.

With regard to clinical symptoms, abdominal pain, nausea and vomiting were seen in almost all cases. Abdominal distension with decreased bowel sounds on auscultation were recognised in about two thirds of the cases, which suggested the impaired peristalsis resulted from amyloid deposit, ${ }^{21}$ a characteristic finding of gastrointestinal amyloidosis.

During the course of diarrhoea, all cases showed severe hypoproteinaemia and hypoalbuminaemia. These results suggested malabsorption $^{22}$ or protein loss. ${ }^{14}$ Moreover, highly increased values of $\mathrm{C}$ reactive protein during the clinical course were pathognomonic of intractable diarrhoea. The increased value of $\mathrm{C}$ reactive protein is assumed to be caused by severe intestinal inflammation. And we speculate that ischaemia of the intestinal mucosa and gastrointestinal infection are the causes of intestinal inflammation. With regard to infection, no causative bacteria such as Shigella, Salmonella, Vibrio or enteropathogenic Escherichia coli were detected in faeces culture. However, we could not perform bacteriological examination of jejunal aspirate. And we did not examine stool toxin of Clostridium difficile in three cases (case 2,16,17) who had been given antibiotics before the onset of intractable diarrhoea. Thus, it cannot be denied that change or increase of some kind of intestinal bacterial flora or viral infection may have triggered the gastrointestinal inflammation.

From these clinical symptoms and abnormal laboratory data, the impaired motility and inflammation of the intestine are assumed to be important pathogenic factors of intractable diarrhoea. It is probable that amyloid infiltration of the intestinal smooth muscle ${ }^{23}$ or gastrointestinal neuropathy with amyloid involvement of the autonomic nerves ${ }^{21}$ caused impaired motility of the intestines.

Abnormal findings were noted in all the patients who underwent gastrointestinal endoscopy. The coarse mucosal appearance reported by $\mathrm{Tada}^{24}$ and Shimada ${ }^{2}$ were observed in $75 \%$ of the cases. These findings are considered to have been caused by amyloid deposits. Although mucosal injuries are highly suggestive of gastrointestinal tract inflammation caused by amyloidosis we must treat these abnormal lesions by considering the possibility that they were induced by drugs such as non-steroidal anti-inflammatory drugs.

Recurrence of intractable diarrhoea was observed in four of 24 cases (six episodes) and onset of ischaemic colitis in two. It was difficult in most of these cases to give anti-rheumatic drugs continuously because of the manifestation of gastrointestinal symptoms such as constipation, diarrhoea, feeling of abdominal fullness or nausea after the remission of the first episode of intractable diarrhoea and adverse reactions. Therefore, these patients sustained high RA activities, leading to the recurrence of gastrointestinal amyloidosis. The patients whose condition worsened and presented symptoms of intestinal pseudoobstruction were very serious, and three of four cases died. The transition from diarrhoea to intestinal pseudo-obstruction is considered as one of the most serious conditions showing severe gastrointestinal dysfunction.

Intractable diarrhoea was treated to allow the impaired intestines some rest and reduce intestinal inflammation. The patients who had severe nausea or vomiting and those with severe hypoproteinaemia received intravenous hyperalimentation in combination with a moderate dose of corticosteroids. Intravenous hyperalimentation was given to suppress exudation from digestive organs and rest the inflamed gastrointestinal tracts. Intravenous hyperalimentation had to be given for a comparatively long period of time until remission, but it was effective in many cases. There are some reports indicating the usefulness of intravenous hyperalimentation for severe diarrhoea caused by amyloidosis. ${ }^{1516}$ Thus intravenous hyperalimentation is considered an appropriate regimen for severe cases. Patients who did not respond to intravenous hyperalimentation treatment and had diarrhoea for a long period of time, were give corticosteroid pulse therapy at the discretion of the physician responsible for care. Decrease of the frequency of diarrhoea or transition of watery diarrhoea to soft faeces was observed early after the end of corticosteroid pulse therapy. Especially, in the case of patients having long term diarrhoea (cases 11 and 12), diarrhoea stopped on days 11 and 3 after the end of corticosteroid pulse therapy, respectively, showing dramatic effects. Corticosteroid pulse therapy is supposed to strongly suppress the generation of SAA and intestinal exudation by reducting systemic and intestinal inflammation. A moderate dose of corticosteroids and corticosteroid pulse therapy are considered clinically effective in cases of diarrhoea caused by amyloidosis. On the other hand, however, corticosteroids are strong immunosuppressive agents, and therefore it is important to use them with caution for a short period of time while paying attention to infectious complications.

As for the causes of death during the course of intractable diarrhoea, the six of seven patients who died, died of infectious diseases. Bacterial translocation, that is, the transfer of bacteria from the intestine to the whole body was supposed to have occurred because of malnutrition and atrophy of intestinal villi caused by amyloid deposits and inflammation of the gastrointestinal mucosa. In addition, intractable diarrhoea is usually associated with hypogammaglobulinaemia, which makes the patients vulnerable to bacterial infections. The most frequent cause of death during the follow up was renal failure (three patients). Renal failure is the main cause of death for patients with secondary amyloidosis; thus, renal dysfunction is a poor prognostic factor in secondary amyloidosis. ${ }^{4825} \mathrm{RA}$ inflammation of the three 
cases who died from renal failure was poorly controlled after remission of intractable diarrhoea and their renal function gradually deteriorated.

As for the long term prognosis, the five year survival rate of the 24 cases, from the onset of intractable diarrhoea, was as low as $38.9 \%$. In particular, the five year survival rates of the 'group having highly increased $\mathrm{C}$ reactive protein values during the course of intractable diarrhoea' and the 'group requiring intravenous hyperalimentation treatment' were extremely low, $11.8 \%$ and $27.4 \%$, respectively.

Why is the prognosis of patients with serious intractable diarrhoea so poor? There were patients who died of infectious diseases during the course of intractable diarrhoea, patients who had nausea or complained of abdominal fullness even after remission of diarrhoea, and patients who had persistent hypoproteinaemia or hypoalbuminaemia and were prone to suffer viral infections, such as herpes zoster, or showed poor compliance with anti-rheumatic drugs. Thus, the state of insufficient control of rheumatoid inflammation persisted and they would eventually develop gastrointestinal dysfunction or renal failure.

1 Friman C, Pettersson T. Amyloidosis. Curr Opin Rheumatol 1996;8:62-71

2 Shimada Y, Tosa H, Terasawa K, Tanaka M. A gastrointestinal endoscopic study on secondary amyloidosis complicating rheumatoid arthritis. Dig Endosc 1992;4:37-49.

3 Tiitinen S, Kaarela K, Helin H, Kautiainen H, Isomaki H. Amyloidosis - Incidence and early risk factors in patients with rheumatoid arthritis. Scand J Rheumatol 1993; 22:158-61.

4 Okuda Y, Takasugi K, Oyama T, Onuma M, Oyama $\mathrm{H}$. Amyloidosis in rheumatoid arthritis: clinical study of 124 Amyloidosis in rheumatoid arthritis: clinical study of 124 34:939-46.

5 Kobayashi H, Tada S, Fuchigami T, Okuda Y, Takasugi K, Matsumoto $\mathrm{T}$, et al. Secondary amyloidosis in patients with rheumatoid arthritis: diagnostic and prognostic value of gastroduodenal biopsy. Br J Rheumatol 1996;35:44-9.

6 Browning MJ, Banks RA, Tribe CR, Hollingworth P, Kingswood C, Mackenzie JC, et al. Ten years' experience of an amyloid clinic - a clinicopathological survey. Q J Med $1985 ; 54: 213-27$
7 Janssen S, Van Rijswijk MH, Meijer S, Ruinen L, Van Der Hem GK, Systemic cases. Neth Med 1986;29:376-85.

8 Gertz MA, Kyle RA. Secondary systemic amyloidosis: response and survival in 64 patients. Medicine 1991; 70:246-56.

9 Glenner GC. Amyloid deposits and amyloidosis. N Engl J Med 1980;302:1283-92.

10 Husby G. Amyloidosis and rheumatoid arthritis. Clin Exp Rheumatol 1985;3:173-80.

11 Kyle RA. Amyloidosis. Baillieres Clin Heamatol 1982; 11:151-80.

12 Legge DA, Wollaeger EE, Carlson HC. Intestinal pseudoobstruction in systemic amyloidosis. Gut 1970;2:764-7.

13 Ishikawa Y, Ishii T, Masuda S, Asuwa N, Kuguchi H. Multiple penetrating colonic ulcers in secondary amyloidosis caused by rheumatoid arthritis. Acta Pathol Jpn 1993; 43:59-64.

14 Kawaguchi M, Koizumi F, Shimao M, Hirose S. Proteinlosing enteropathy due to secondary amyloidosis of the gastrointestinal tract. Acta Pathol Jpn 1993;43:333-9.

15 Maruyama K, Akamatsu T, Owa O, Nakamura N, Fujimori $\mathrm{Y}$, Hasebe $\mathrm{O}$, et al. A case of secondary amyloidosis with clinical symptoms of acute enteritis (in Japanese). Endosc Forum Dig Dis 1993;9:284-8.

16 Ozawa T, Sato T, Nakano M, Arakawa M, Murasawa A. Cyclophosphamide and prednisolone treatment in gasCyclophosphamide and prednisolone treatment in gas(in Japanese). J Chubu Rheum Assoc 1993;24:136-7.

17 Hashimoto $M$, Shingu M, Yoshikawa Y, Nonaka S, Wada T, Ichibanngase $\mathrm{Y}$, et al. Amyloidosis of the small intestine secondary to rheumatoid arthritis and juvenile rheumatoid arthritis; reports of two cases (in Japanese). Ryumachi 1995;35:100-6.

18 Arnett FC, Edworthy SM, Bloch DA, McShane DJ, Fries $\mathrm{JF}$, Cooper NS, et al. The American Rheumatism Association 1987 revised criteria for the classification of rheumatoid arthritis. Arthritis Rheum 1988;31:315-24.

19 Lansbury J.Clinical appraisal of the activity index as a measure of rheumatoid activity. Arthritis Rheum 1968;11:599605.

20 Falck HM, Maury CPJ, Teppo AM, Wegelius O. Correlation of persistently high serum amyloid $A$ protein and C-reactive protein concentrations with rapid progression of secondary amyloidosis. BMJ 1983;286:1391-3.

21 Battle WM, Rubin MR, Cohen S, Snape WJ Jr. Gastrointestinal-motility dysfunction in amyloidosis. N JastroMed 1979;301:24-5.

22 Petterson T, Wegelius O. Biopsy diagnosis of amyloidosis in rheumatoid arthritis. Malabsorption caused by intestinal amyloid deposits. Gastroenterology 1972;62:22-7.

23 Gilat T, Spiro HM. Amyloidosis and the gut. Am J Dig Dis 1968;13:619-33.

24 Tada S, Iida M, Iwashita A, Matsui T, Fuchigami T, Yamamoto $\mathrm{T}$, et al. Endoscopic and biopsy findings of the Yamamoto T, et al. Endoscopic and biopsy findings of the upper digestive tract in patien.

25 Hazenberg BC, Van Rijswijk MH. Clinical and therapeutic aspects of AA amyloidosis. Baillieres Clin Rheumatol $1994 ; 8: 661-90$ 